\section{Tumour recurrence is associated with Jass grouping but not with differences in E-cadherin expression in moderately differentiated Dukes' B colorectal cancers}

\author{
M Ilyas, M Novelli, K Wilkinson, I P M Tomlinson, A M Abbasi, A Forbes, I C Talbot
}

\begin{abstract}
Aims-To assess whether immunohistochemical expression of the putative invasion suppressor, E-cadherin, is associated with tumour recurrence in colorectal cancer, independent of Dukes' stage and degree of differentiation, and thus to determine whether measurement of E-cadherin is clinically useful.

Methods-90 moderately differentiated Dukes' B colorectal carcinomas from patients who had been followed up for at least six years were examined. All were from curative resections performed at $\mathrm{St}$ Mark's Hospital and the tumours were shown, on histology, to be clear of all resection margins. Tumours were reviewed and additionally classified in accordance with the Jass grouping system. Immunohistochemical analysis of E-cadherin expression was performed for each tumour using the monoclonal antibody HECD 1.
\end{abstract}

Colorectal Cancer Unit, Imperial Cancer Research Fund, St Mark's Hospital, Watford Road, Harrow HA1 3UJ

$M$ Ilyas

I C Talbot

Cancer Genetics Laboratory, Imperial Cancer Research Fund 44 Lincoln's Inn Fields, London WC2A 3PX

M Novelli

I P M Tomlinson

Department of

Research Records, St Mark's Hospital, Watford Road, Harrow

HA1 3UJ

$\mathrm{K}$ Wilkinson

Department of Gastroenterology, St Mark's Hospital, Watford Road, Harrow HA1 3UJ

A M Abbasi

A Forbes

Correspondence to: Dr M Ilyas.

Accepted for publication 10 December 1996 therefore present at an advanced stage. With the number of available treatment methods constantly increasing and with the prospect of gene therapy, there is an increasing need to identify markers of tumour behaviour which are independent of (and thereby give additional information on) tumour stage and grade. The genetic basis of colorectal cancer has been an area of intense scientific interest and a postulated model of tumour development for sporadic colorectal cancers has been generally accepted. ${ }^{3}$ Mutations of the p53 gene are a common step in this model, and can be detected with relative ease and reliability as immunohistochemical overexpression of the p53 protein. ${ }^{4}$ Studies which have investigated the value of $\mathrm{p} 53$ overexpression as a prognostic indicator have given conflicting results. ${ }^{5-9}$ This is not altogether surprising since p53 mutation seems to be important for the transition from a late adenoma to an invasive carcinoma rather than for evolution of the tumour after invasion. $^{3}$

E-cadherin is a member of a large family of calcium dependent adhesion molecules. ${ }^{10}{ }^{11} \mathrm{It}$ exists as a monomeric transmembrane molecule which is capable of homotypic recognition and formation of adherens junctions. It is important in controlling cell motility during embryogenesis and tissue healing. ${ }^{10-12}$ It may also be important in controlling the cell cycle through contact inhibition and apoptosis. ${ }^{13}$ The cytoplasmic tail of E-cadherin complexes with $\alpha, \beta$, and $\gamma$ catenins $^{1415}$ to form the E-cadherin-catenin unit (ECCU). This unit is then thought to bind to the actin cytoskeleton.

Wild-type E-cadherin may be important in preventing the development of invasive properties in tumours. Loss of E-cadherin expression and mutations of the E-cadherin gene (HSECAD) have been shown in several different invasive epithelial tumours. ${ }^{16-20}$ In vitro transfection and expression of full length $\mathrm{E}$-cadherin cDNA in invasive, E-cadherin deficient cell lines have been shown to result in loss of invasive features in these cell lines. ${ }^{21}$ In colorectal carcinoma, however, the importance of E-cadherin in tumour invasion is uncertain. Most studies have shown that loss of E-cadherin expression occurs in parallel with increases in tumour stage and grade. ${ }^{22-24}$ Other studies have provided data which are difficult to interpret, such as high expression of E-cadherin in intravascular components of world. ${ }^{1}$ The Dukes' staging system and the Jass grouping system ${ }^{2}$ are excellent predictors of prognosis. These systems are, however, to some degree tautologous-that is, a high grade tumour is more likely to invade through the bowel wall and metastasise to lymph nodes and 
some tumours which have low expression in the extravascular tumour, ${ }^{25}$ and similar degrees of E-cadherin expression in primary and metastatic tumours. ${ }^{26}$ These data, together with the fact that few HSECAD mutations have been described in colonic tumours, suggest that changes in E-cadherin protein expression may play a role in colon tumour progression at various times, but do not determine how and why this occurs.

It is not essential for the role of E-cadherin in cancers to be understood completely for it to be a useful indicator of patient outcome. In one study, ${ }^{27} \mathrm{E}$-cadherin expression was shown to be a potentially useful indicator of prognosis in Dukes' B colon cancers. This analysis did not, however, control for the degree of tumour differentiation. It is possible, therefore, that the observed association between E-cadherin and prognosis was not independent of tumour grade. Irrespective of its biological role in tumorigenesis, there is little point in using E-cadherin immunohistochemistry as a measure of prognosis, if routinely measured variables-Dukes' stage and grade (degree of differentiation)-provide just as good an assessment of outcome. This is particularly true for moderately differentiated Dukes' B colon cancers, which have the most uncertain prognosis and for which additional indicators of outcome would be very valuable.

We have therefore assessed E-cadherin expression using immunohistochemistry in 90 cases of moderately differentiated Dukes' B colon cancer to determine whether E-cadherin is a useful independent indicator of prognosis in this group of patients. We also determined whether the extra variables incorporated into the Jass grouping predicted outcome in these cases. Postoperative follow up data were available for at least six years for each patient.

\section{Methods}

CASE SELECTION

Ninety eight Dukes' B colorectal cancers were retrieved from the archives of St Mark's Hospital. All the operations had been performed at St Mark's Hospital and in each case with curative intent. On pathological examination, all tumours were shown to be clear of all resection margins. The tumours were reviewed independently by two pathologists and 90 cases that were moderately differentiated according to gland formation and nuclear pleomorphism were selected for further analysis.

\section{JASS GRADING}

The selected cases were classified in accordance with the Jass grouping system. ${ }^{2}$ This system scores four features of the tumour: degree of invasion through the bowel wall (transmural invasion $=1$, limited to bowel wall $=0$ ); margin of the tumour (infiltrating margin $=1$, pushing margin $=0$ ); peritumoral lymphocytic infiltrate (scant/absent infiltrate = 1 , conspicuous infiltrate $=0$ ); lymph node metastasis $(>4$ involved nodes $=2,1-4$ involved nodes $=1$, no node involvement $=0$ ). The scores are then summated and the tumours grouped in accordance with the final

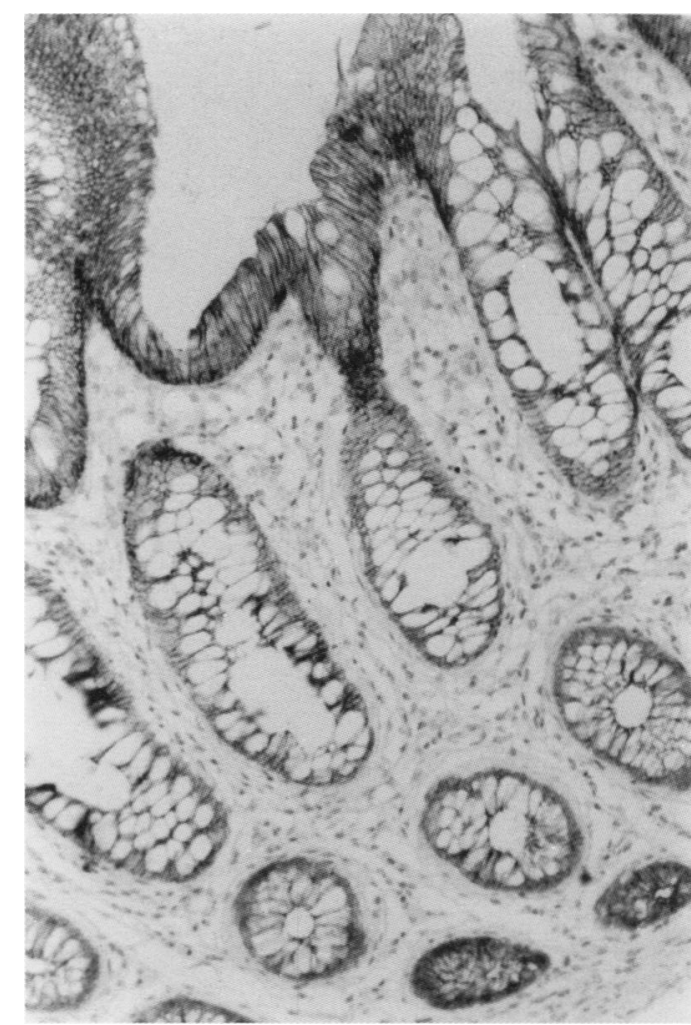

Figure 1 Immunohistochemical E-cadherin expression in non-neoplastic mucosae from patients with sporadic colorectal carcinoma. There is punctate membranous expression along the whole length of the crypt. (Magnification $\times 190$.)

score (group I $=0 / 1$; group II $=2$; group III = 3 ; group IV $=4 / 5$ ). Since these tumours were Dukes' B cases they were all classified between group I and III. The tumour margins and lymphocytic infiltrate were assessed independently by the two pathologists and any cases in which there was disagreement were then reviewed together and a Jass group was agreed.

\section{IMMUNOHISTOCHEMISTRY}

Immunohistochemical analysis was performed on representative blocks of formalin fixed paraffin embedded tumour tissue from each case. Freshly cut $4 \mu \mathrm{m}$ thick sections were dewaxed in xylene and rehydrated through graded alcohols. Endogenous peroxidase activity was blocked by incubation for 15 minutes in $0.5 \%$ hydrogen peroxide in methanol. Antigen retrieval was by heating these sections in a pressure cooker at 15 psi for 30 minutes in sodium citrate solution (0.1 M, pH 6.0). Sections were incubated for 30 minutes with normal rabbit serum (Dako) and were then incubated overnight at room temperature with a mouse monoclonal antibody for E-cadherin (HECD-1, ICRF). After washing in phosphate buffered saline (PBS), sections were incubated for one hour each with biotinylated rabbit antimouse (Dako) and horseradish peroxidase labelled streptavidin (Dako), respectively (1:200 dilution for each). Diaminobenzedene hydrochloride (DAB) was used as the chromogen, and negative controls (performed by using PBS buffer instead of the primary antibody) were included in each experiment. Normal tissue present in the tumour section was used as a positive control. The immunohis- 


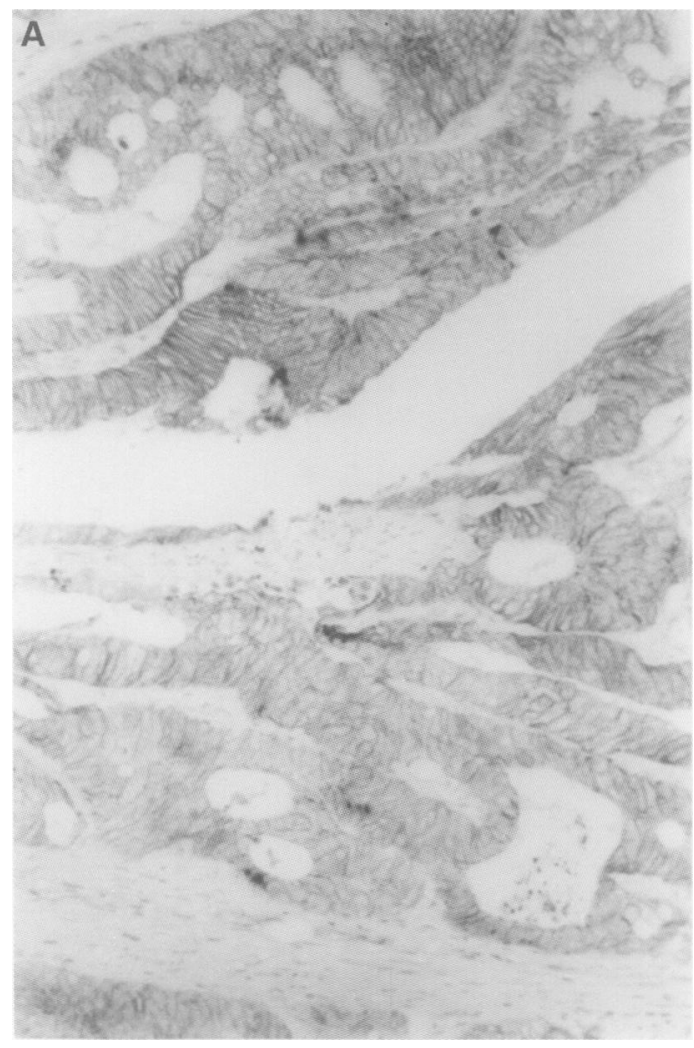

Figure 2 Immunohistochemical expression of E-cadherin in moderately differentiated colorectal cancer.

(A) Membranous expression in most cells of the tumours.

(B) Heterogeneous expression. Some, but not all, tumour cells show membranous expression. (C) Membranous expression of E-cadherin in clumps of tumour cells in a mucinous carcinoma (arrowed). (Magnification $(A) \times 154$, (B) $\times 193,(C) \times 242$.)
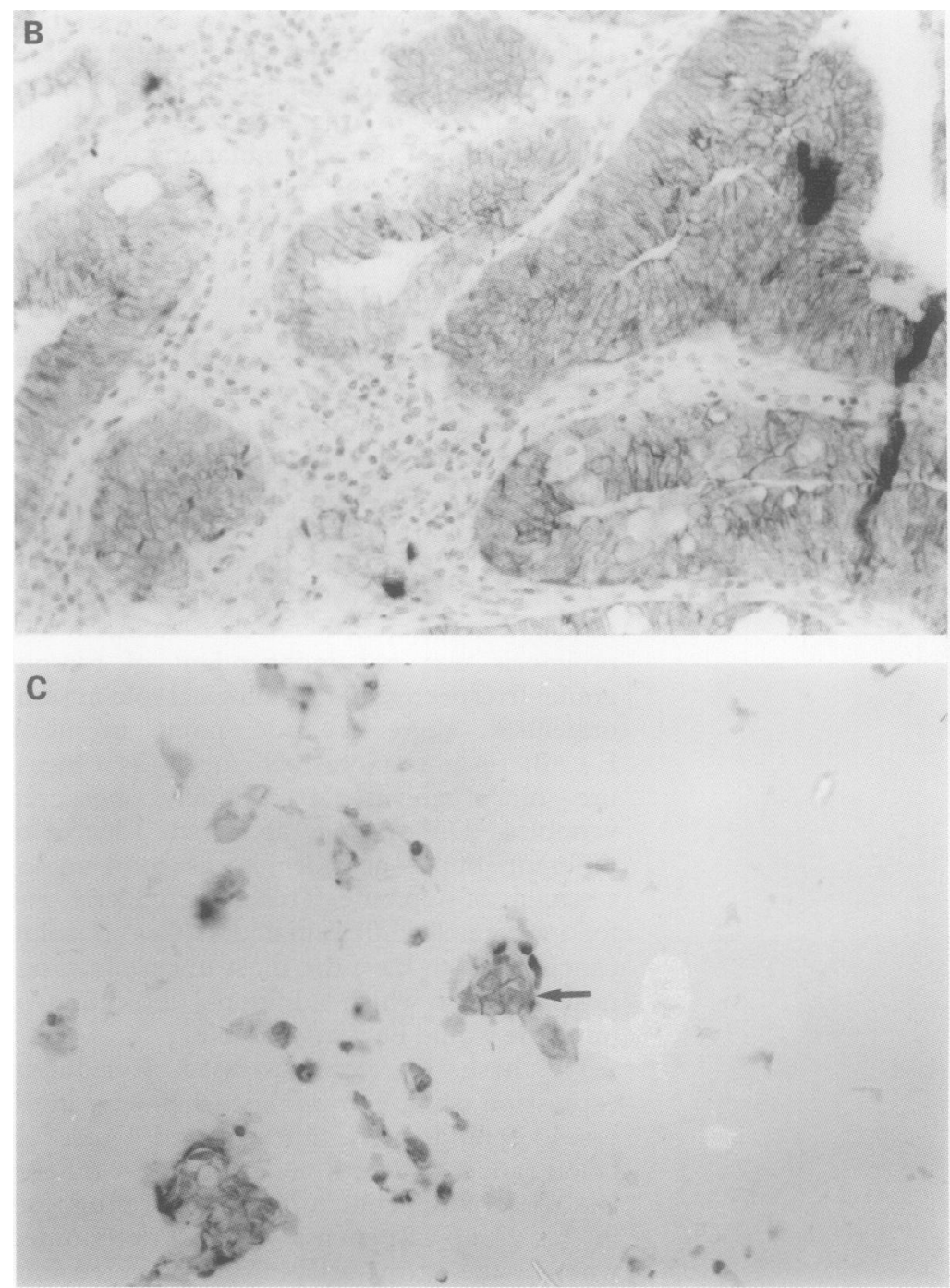

tochemistry was reviewed independently by two pathologists who were unaware of the categorisation of the tumours. Only membrane staining was regarded as positive staining and the tumours were scored semiquantitatively using a scoring system of $0=0 \% ;+=<25 \%$; $++=25-50 \% ;+++=>50 \%$ of tumour cells. Cases in which there was a discrepancy in the scoring were reviewed by both pathologists together and a final score agreed.

DATA ANALYSIS

The results of the immunostaining and the Jass grouping for each tumour were analysed by KW and IPMT. They alone had access to data regarding the outcome of each individual case and at no stage was either of the pathologists made aware of these data. Immunostaining and Jass group were each correlated with tumour recurrence and were then correlated with each other.

\section{Results}

Table 1 shows the correlation of Jass group with tumour recurrence and table 2 shows correlation of E-cadherin immunostaining with tumour recurrence. Normal epithelium showed punctate basolateral membrane staining for E-cadherin along the whole length of the crypt (fig 1) and this served as an internal positive control. Most tumours showed heterogeneous staining with variable degrees of both membrane and cytoplasmic staining (fig 2). In some areas there was intense cytoplasmic staining with no membrane staining and a few cases were negative for both cytoplasmic and membrane staining (fig 3). Only cells with membrane staining were regarded as being positive for E-cadherin expression, since membrane localisation is essential to E-cadherin function. Cases which showed membrane staining in less than $25 \%$ of tumour cells were regarded as negative for E-cadherin staining and results were analysed using this criterion.

There was a statistically significant correlation between Jass grouping and tumour recurrence $(p<0.05)$. Forty out of 69 of the non-recurrent tumours (58\%) and $13 / 21$ of the recurrent tumours $(62 \%)$ were positive for E-cadherin expression. There was no association between loss of E-cadherin expression and tumour recurrence. There was also no association between the Jass group and E-cadherin expression (tables 3, 4).

\section{Discussion}

We investigated the value of immunohistochemical E-cadherin expression as a predictor of tumour recurrence in moderately differentiated Dukes' B colorectal carcinoma and 

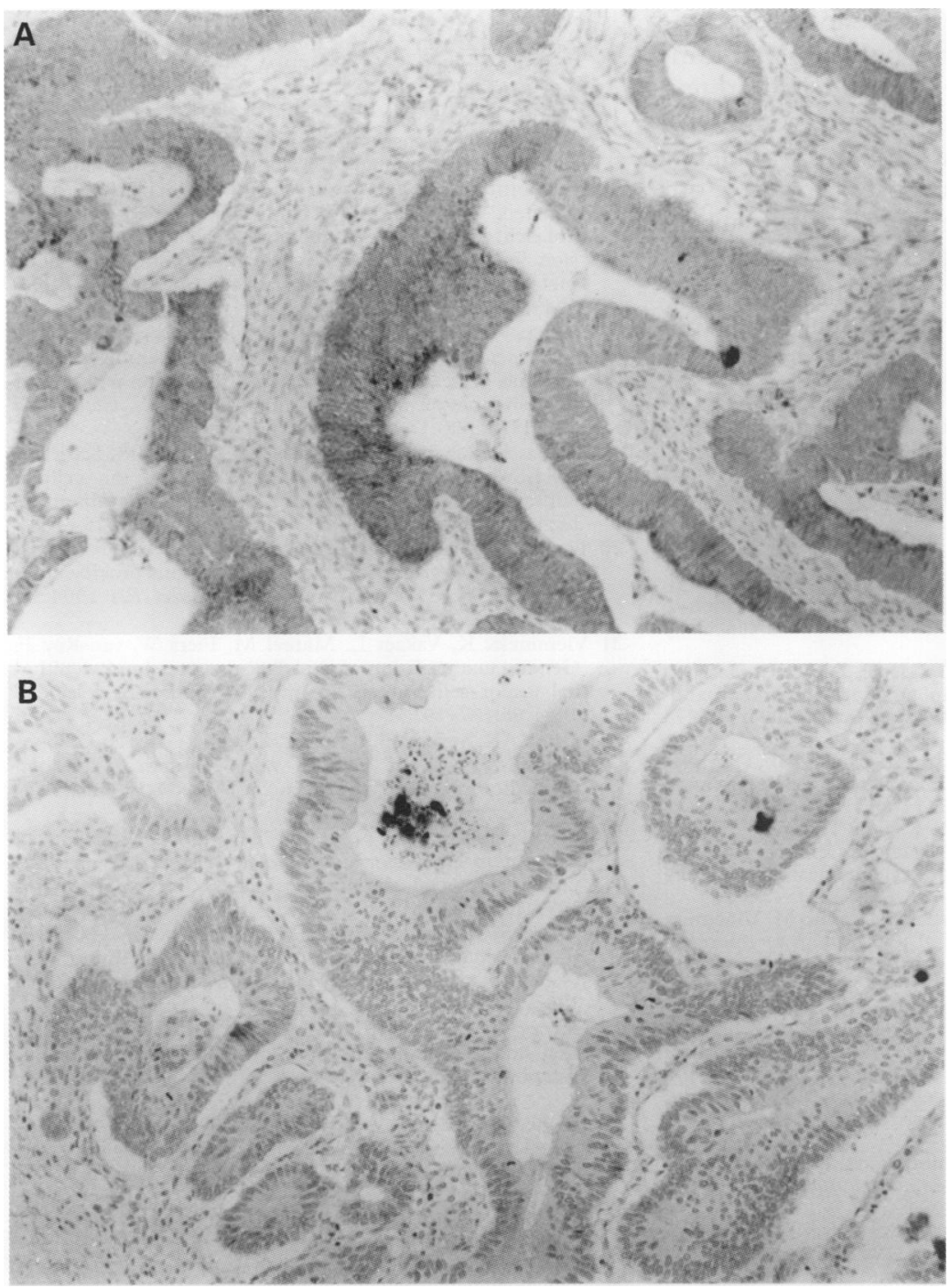

Figure 3 Immunohistochemical expression of E-cadherin in moderately differentiated colorectal cancer. $(A)$ Intense cytoplasmic expression without membranous expression. This tumour would be regarded as negative for E-cadherin expression since membrane localisation is essential for function of E-cadherin. (B) A tumour which is completely negative for E-cadherin expression. (Magnification $(A)$ and $(B) \times 152$.)

Table 3 Correlation of fass grouping with E-cadherin immunostaining

\begin{tabular}{llllll}
\hline \multirow{5}{*}{ fass group } & \multicolumn{4}{l}{ E-cadherin staining } \\
\cline { 2 - 6 } & 0 & + & ++ & +++ & Total \\
\hline I & $1(17 \%)$ & $7(23 \%)$ & $5(13 \%)$ & $0(0 \%)$ & $13(14 \%)$ \\
II & $2(33 \%)$ & $20(65 \%)$ & $21(54 \%)$ & $12(86 \%)$ & $55(61 \%)$ \\
III & $3(50 \%)$ & $4(12 \%)$ & $13(33 \%)$ & $2(14 \%)$ & $22(25 \%)$ \\
Total & 6 & 31 & 39 & 14 & 90 \\
\hline
\end{tabular}

Pearson $\chi_{6}^{2}=11.2185, \mathrm{p}>0.05$

compared this with the Jass prognostic grouping. E-cadherin expression was not associated with outcome in these patients and therefore provided no additional useful prognostic information. Jass group was, however, associated with outcome, showing that the features incorporated in the Jass grouping provide useful additional information independent of Dukes' stage and the degree of differentiation. No correlation was seen between E-cadherin immunostaining and Jass grouping. These results suggest that, for clinical purposes, it is useful to measure a colon cancer's Jass group in addition to Dukes' stage and degree of differentiation, but that measurement of E-cadherin expres-
Table 1 Correlation of fass grouping with tumour recurrence

\begin{tabular}{llll}
\hline & \multicolumn{3}{l}{ Patient status } \\
\cline { 2 - 4 } Fass group & No recurrence & Recurrence & Total \\
\hline I & $13(19 \%)$ & $0(0 \%)$ & $13(14 \%)$ \\
II & $42(61 \%)$ & $13(62 \%)$ & $55(61 \%)$ \\
III & $14(20 \%)$ & $8(38 \%)$ & $22(25 \%)$ \\
Total & 69 & 21 & 90 \\
\hline
\end{tabular}

Pearson $\chi_{2}^{2}=6.0474, \mathrm{p}<0.05$.

Table 2 Correlation of E-cadherin immunostaining with tumour recurrence

\begin{tabular}{llll}
\hline & \multicolumn{2}{l}{ Patient status } & \\
\cline { 2 - 4 } E-cadherin staining & No recurrence & Recurrence & Total \\
\hline 0 & $4(6 \%)$ & $2(9 \%)$ & $6(7 \%)$ \\
+ & $25(36 \%)$ & $6(29 \%)$ & $31(34 \%)$ \\
++ & $30(43 \%)$ & $9(43 \%)$ & $39(43 \%)$ \\
+++ & $10(15 \%)$ & $4(19 \%)$ & $14(16 \%)$ \\
Total & 69 & 21 & 90 \\
Negative $(0 /+)$ & $29(42 \%)$ & $8(38 \%)$ & $37(41 \%)$ \\
Positive $(++++++)$ & $40(58 \%)$ & $13(62 \%)$ & $53(59 \%)$ \\
\hline
\end{tabular}

Pearson $\chi_{3}^{2}=0.8259, \mathrm{p}>0.8$.

Pearson $\chi^{2}{ }_{1}[0,+v++,+++]=0.1029, \mathrm{p}>0.748$.

sion is unlikely to provide useful additional information.

Our results are consistent with the results of Gagliardi $e t a l^{28}$ and may clarify the findings of Dorudi et $a l,{ }^{27}$ who found a significant correlation between E-cadherin expression and clinical outcome in a smaller sample of Dukes' B colorectal cancers (some of which we believe were also analysed here). The tumours of Dorudi et $a l^{27}$ were not controlled for degree of differentiation and were investigated using in situ hybridisation for mRNA. This method depends, in part, on mRNA stability and does not indicate protein synthesis or localisation (membranous versus cytoplasmic). Since membrane localisation is essential to E-cadherin function, a strong mRNA signal will not necessarily correlate with E-cadherin protein function. In our study, only membrane staining was considered as positive, and an intense cytoplasmic signal in the absence of membrane staining was regarded as negative. It remains possible that E-cadherin expression provides useful additional prognostic information in well and poorly differentiated colon cancers, or in Dukes' A and C cancers. In general, however, these tumours have a more predictable outcome than moderately differentiated Dukes' B cases and for this reason there is unlikely to be great value in studying E-cadherin in such cancers.

The fact that E-cadherin expression is probably not a useful independent indicator of out-

Table 4 Correlation of Fass grouping with E-cadherin immunostaining

\begin{tabular}{|c|c|c|c|}
\hline \multirow[b]{2}{*}{ fass group } & \multicolumn{3}{|c|}{ E-cadherin staining } \\
\hline & $\begin{array}{l}\text { Negative } \\
(\mathrm{O}++)\end{array}$ & $\begin{array}{l}\text { Positive } \\
(++/+++)\end{array}$ & Total \\
\hline $\begin{array}{l}\text { I } \\
\text { II } \\
\text { III }\end{array}$ & $\begin{array}{l}8(22 \%) \\
22(60 \%) \\
7(19 \%)\end{array}$ & $\begin{array}{l}5(10 \%) \\
33(62 \%) \\
15(28 \%)\end{array}$ & $\begin{array}{l}13(14 \%) \\
55(61 \%) \\
22(25 \%)\end{array}$ \\
\hline Total & 37 & 53 & 90 \\
\hline
\end{tabular}

Pearson $\chi_{2}^{2}=3.0535, \mathrm{p}>0.2$. 
come in colorectal cancer does not necessarily have implications for its biological role in tumorigenesis. For example, E-cadherin protein may be involved in pathways that influence tumour stage and grade and thus influence prognosis. For clinical purposes, however, our data suggest that $E$-cadherin provides no useful extra information when predicting outcome in patients with moderately differentiated Dukes' $\mathrm{B}$ colorectal carcinomas, and probably in other colon cancers as well.

1 Potter JD, Slattery ML, Bostick RM, Gapstur SM. Colon cancer: a review of the epidemiology. Epidemiol Rev 1993;15:499-545.

2 Jass JR, Love SB, Northover JM. A new prognostic classification of rectal cancer. Lancet 1987;i:1303-6.

3 Fearon ER, Vogelstein B. A genetic model for colorectal tumorigenesis. Cell 1990;61:759-67.

4 Costa A, Marasca R, Valentinis B, Savarino M, Faranda A Silvestrini $R$, et al. p53 gene point mutations in relation to p53 nuclear protein accumulation in colorectal cancers. $f$ Pathol 1995;176:45-53.

5 Nathanson SD, Linden MD, Tender P, Zarbo RJ, Jacobsen G, Nelson LT. Relationship among p53, stage, and prognosis of large bowel cancer. Dis Colon Rectum 1994;37:52734.

6 Scott N, Sagar P, Stewart J, Blair GE, Dixon MF, Quirke P. p53 in colorectal cancer: clinicopathological correlation and prognostic significance Brf Cancer 1991;63:317-9.

7 Suzuki H, Matsumoto K, Koide A, Tada T, Fujino I, Okuda $\mathrm{A}$, et al. Correlation of $\mathrm{p} 53$ with the clinicopathologic features and prognosis of colorectal adenocarcinoma. Surg Today 1994;24:85-7.

8 Yamaguchi A, Kurosaka Y, Fushida S, Kanno M, Yonemura Y, Miwa K, et al. Expression of p 53 protein in colorectal cancer and its relationship to short-term prognosis. Cancer 1992;70:2778-84.

9 Zeng ZS, Sarkis AS, Zhang ZF, Klimstra DS, Charytonowicz E, Guillem JG, et al. p53 nuclear overexpression: an independent predictor of survival in lymph node-positive colorectal cancer patients. F Clin Oncol 1994;12:2043-50.

10 Takeichi M. The cadherins: cell-cell adhesion molecules controlling animal morphogenesis. Development 1988;102 639-55.

11 Takeichi $M$. Cadherins: a molecular family important in selective cell-cell adhesion. Annu Rev Biochem 1990;59: 237-52.

12 Dogan A, Wang ZD, Spencer J. E cadherin expression in intestinal epithelium. 7 Clin Pathol 1995;48:143-6.

13 Cowin P. Unraveling the cytoplasmic interactions of the cadherin superfamily. Proc Natl Acad Sci USA 1994;91: 10759-61.

14 Gumbiner BM, McCrea PD. Catenins as mediators of the cytoplasmic functions of cadherins. $\mathcal{f}$ Cell Sci Suppl 1993;17:155-8.
15 Hinck L, Nathke IS, Papkoff J, Nelson WJ. Dynamics of cadherin/catenin complex formation: novel protein interactions and pathways of complex assembly. $\mathcal{F}$ Cell Biol 1994; 125: $1327-40$.

16 Oka H, Shiozaki H, Kobayashi K, Inoue $M$, Tahara H, Kobayashi T, et al. Expression of E-cadherin cell adhesion molecules in human breast cancer tissues and its molecules in human breast cancer tissues and its

17 Pignatelli M, Ansari TW, Gunter P, Liu D, Hirano S, Takeichi M, et al. Loss of membranous E-cadherin expression in pancreatic cancer: correlation with lymph node metastasis, high grade, and advanced stage. $\mathcal{F}$ Pathol 1994; 174:243-8.

18 Schipper JH, Frixen UH, Behrens J, Unger A, Jahnke K, Birchmeier W. E-cadherin expression in squamous cell carcinomas of head and neck: inverse correlation with tumor dedifferentiation and lymph node metastasis. Cancer Res 1991;51:6328-37.

19 Umbas R, Schalken JA, Aalders TW, Carter BS, Karthaus HF, Schaafsma HE, et al. Expression of the cellular adhesion molecule E-cadherin is reduced or absent in high-grade prostate cancer. Cancer Res 1992;52:5104-9.

20 Becker KF, Atkinson MJ, Reich U, Becker I, Nekarda H, Siewert JR, et al. E-cadherin gene mutations provide clues to diffuse type gastric carcinomas. Cancer Res 1994;54: 3845-52.

21 Vleminckx K, Vakaet L, Mareel M, Fiers W, van-Roy F. Genetic manipulation of E-cadherin expression by epithelial tumor cells reveals an invasion suppressor role. Cell 1991;66:107-19.

22 Nigam AK, Savage FJ, Boulos PB, Stamp GW, Liu D, Pignatelli $M$. Loss of cell-cell and cell-matrix adhesion molecules in colorectal cancer. Br $\mathcal{F}$ Cancer 1993;68:50714.

23 Kinsella AR, Lepts GC, Hill CL, Jones M. Reduced E-cadherin expression correlates with increased invasiveness in colorectal carcinoma cell lines. Clin Exp Metastasis 1994;12:335-42.

24 Dorudi S, Sheffield JP, Poulsom R, Northover JM, Hart IR. E-cadherin expression in colorectal cancer. An immunocytochemical and in situ hybridization study. Am 7 Pathol 1993;142:981-6.

25 Cowley GP, Smith ME. Modulation of E-cadherin expression and morphological phenotype in the intravascular component of adenocarcinomas. Int $f$ Cancer 1995;60:325-

26 van-der-Wurff AA, Arends JW, van-der-Linden EP, tenKate J, Bosman FT. L-CAM expression in lymph node and liver metastases of colorectal carcinomas. $\mathcal{f}$ Pathol 1994; 172:177-81.

27 Dorudi S, Hanby AM, Poulsom R, Northover J, Hart IR. Level of expression of E-cadherin mRNA in colorectal cancer correlates with clinical outcome. Br f Cancer 1995;71: 614-6.

28 Gagliardi G, Kandemir O, Liu D, Guida M, Benvestito S, Ruers $\mathrm{T}$, et al. Changes in E-cadherin immunoreactivity in the adenoma-carcinoma sequence of the large bowel. Virchows Arch 1995;426:149-54. 